\title{
Hydrogenated In-doped ZnO Thin Films for the New Anode Material of Organic Light Emitting Devices: Synthesis and Application Test
}

\author{
Young Ran Park, Eunkyoung Nam, Jin-Hyo Boo, ${ }^{+*}$ Donggeun Jung, Su Jeong Suh, ${ }^{+}$and Young Sung Kim ${ }^{+* *}$ \\ Department of Physics, Institnte of Basic Science and Center for Nanotubes and Nanocomposites, \\ Sungkninkwan (niversity, Sinon 440-746, Korea \\ "Department of Chemistry and Institute of Basic Science, Sungkynkwan University, Sinwon 440-746, Korea \\ "E-mail:jhboo@skku.edu \\ ${ }^{+}$Advanced Material Process of Information Technology, Sungkvunkwan University, Suwon 440-746, Korea \\ "E-mail: youngsk@skku.edu \\ Received September 19, 2007
}

\begin{abstract}
Transparent In-doped ( 1 at.\%) zinc oxide (IZO) thin films are deposited by pulsed DC magnetron sputtering with $\mathrm{I}_{2}$ mixed $\Lambda \mathrm{r}$ atmosphere on glass substrate without any heating process. Even at room temperature, highly $c$-axis oriented IZO thin films were grown in perpendicular to the substrate. The hydrogenated IZO (IZO:II) film isolated in $\mathrm{I}_{2}$ atmosphere for $30 \mathrm{~min}$ exhibited an average optical transmittance higher than $85 \%$ and low electrical resistivity of less than $2.7 \times 10^{-3} \Omega \cdot \mathrm{cm}$. These values are comparable with those of commercially available ITO. Each of the IZO films was used as an anode contact to fabricate organic light-emitting diodes (OLEDs) and the device performances studied. $\Lambda$ t the current density of $1 \times 10^{3} \Lambda / \mathrm{m}^{2}$, the OLEDs with IZO:II ( $\mathrm{II}_{2}$ ) anode show excellent efficiency $\left(11 \mathrm{~V}\right.$ drive voltage) and a good brightness $\left(8000 \mathrm{~cd} / \mathrm{m}^{2}\right)$ of the light emitted from the devices, which are as good as the control device built on a commercial ITO anode.
\end{abstract}

Key Words : Indium doped zinc oxide (IZO), Hydrogen effect, Organic light emitting diodes (OLEDs), Pulsed DC magnetron sputtering. Transparent conducting oxide

\section{Introduction}

Potential applications of organic light emitting diodes (OLEDs) have driven widespread efforts to fabricate various kinds of OLEDs with high brightness and high efficiency. Among the several parts of OLEDs, transparent conducting oxide films have been extensively studied because they exhibit high optical transparency and electrical conductivity, and are often used in photoelectronic devices such as solar cells and flat panel displays (FPDs).,3 Tin-doped indium oxides (ITO) have been mainly used as anodes in FPDs because of their high conductivity and transparency over the visible range and their high work function. However, the toxic nature and high cost due to the scarcity of indium have led researchers to seek an alternative candidate for $\mathrm{ITO}^{4}$ Recently, $\mathrm{ZnO}$ or impurity doped $\mathrm{ZnO}$ have been actively investigated as alternative materials to ITO because $\mathrm{ZnO}$ is a nontoxic, inexpensive, and abundant material. ${ }^{5,6}$ Generally, $\mathrm{ZnO}$ is an $n$-type oxide semiconductors, the main defects in the crystal are $\mathrm{Zn}$ interstitials $\left(\mathrm{Zn}_{i}\right)$ and oxygen vacancies $\left(\mathrm{V}_{\mathrm{O}}\right)$. These defects in $\mathrm{ZnO}$ are easily ionized, and electrons produced by ionized defects contribute to the electrical conductivity. Thus, $\mathrm{Zn}_{i}$ and $\mathrm{V}_{O}$ play important roles in the $\mathrm{ZnO}$ film's electrical conductivity and act as donors in the crystal. Many researchers observed that during the deposition process of $\mathrm{ZnO}$ films, the supply of $\mathrm{O}_{2}$ affects the microstnuctual and electrical properties, ${ }^{7-9}$ and therefore demands a careful optimization. In addition, a previous report shows that the decrease of resistivity by vacuum annealing is attributed to the increase of $V_{0}$ in the undoped $\mathrm{TiO}_{2}$ semiconductors. ${ }^{10}$

$\mathrm{Al}$ doped $\mathrm{ZnO}$ thin films have been considered as suitable anodes because $\mathrm{Al}$ doped $\mathrm{ZnO}$ thin films are more stable in reducing ambient in comparison with the ITO films, which make them appropriate for potential use as anodes in OLEDs. ${ }^{11,12}$ Also, various $\mathrm{ZnO}$ nanostructures (e.g., nanoparticle, nanowire, nanorod, and nanosheet) are a suitable material to fabricate the photoanode of dye-sensitized solar cells (DSSCs). . $^{13,14}$

In the last decade, moreover, $\mathrm{ZnO}$ films doped with impurities, such as $\mathrm{Al}, \mathrm{Ga}$, In and $\mathrm{Zr}$, have been actively studied. ${ }^{11,12,15-17}$ Since the utilization possibility of In-doped $\mathrm{ZnO}$ (IZO) thin films grown on glass substrates as anodes in OLEDs is strongly affected by the electrical, optical, and electronic properties, it is very important to study about transparent conducting properties of IZO films for improving the efficiencies of OLEDs. However, no previous reports on hydrogen controlled atmospheric effect after the deposition of IZO thin films have been found.

In this work, therefore, to investigate the effect of atmospheric controlled hydrogen on the physical properties of the films, hydrogenated In-doped $\mathrm{ZnO}$ (IZO:H) films were grown without any heating process by pulsed DC magnetron sputtering method for the flexible substrate application of OLEDs. In addition, the work functions of the as-grown hydrogenated IZO films were investigated and the performance characteristics of OLEDs with various atmospheric hydrogen controlled IZO films as anode were also compared with those of a commercial anodic ITO film. 


\section{Experimental}

IZO films were deposited on glass by asymmetrical bipolar pulsed DC magnetron sputtering, maintaining the chamber pressure at $7 \mathrm{~m}$ Torr during the sputtering. The targets were prepared by sintering the mixed $\mathrm{ZnO}$ and $\mathrm{In}_{3} \mathrm{O}_{3}$ powders ( $4 \mathrm{~N}$ purity each) with In fraction of 1 at. $\%$. The sputtering chamber was pumped down less than $1 \times 10^{-6}$ Torr by turbo molecular pump. During sputtering, the DC power and $\mathrm{DC}$ pulsed frequency as well as substrate to target distance and substrate temperature were kept at $50 \mathrm{~W}, 30$ $\mathrm{kHz}, 7 \mathrm{~cm}$, and room temperature, respectively. During the pure IZO film deposition, the sputtering gas was only used $\mathrm{Ar}$ gas without hydrogen. The IZO:H films were used as a fixed $\mathrm{H}_{2} /\left(\mathrm{H}_{2}+\mathrm{Ar}\right)$ flow ratio of 0.33 between $\mathrm{H}_{2}$ and $\mathrm{Ar}$ gasflow rates with fixed total $\left(\mathrm{H}_{2}+\mathrm{Ar}\right)$ flow rate. Particularly, we attempted to control over the chamber condition of the optimized process condition after the film deposition, which is a way to investigate the hydrogen effects on the_IZO films in the isolating condition. Of the two IZO films incorporated with hydrogen during the sputtering, the one is maintained under a condition of ultra high vacuum (UHV) and the other is maintained under a condition of $\mathrm{H}_{2}$ atmosphere $(50$ mTorr) in the chamber for $30 \mathrm{~min}$ after deposition. The thicknesses of deposited films determined by the field emission scanning electron microscopy (FESEM) were in the range of $200 \pm 10 \mathrm{~nm}$.

In order to detemnine the suitability of an anodic material in OLEDs, the work functions of ITO, pure IZO, and IZO:H films were measured by using a digital Kelvin probe (see Table 1). We have used IZO thin films as an anode contact for OLED devices. The structures of OLEDs were performed as aluminum ( $\mathrm{Al}$ ), lithium fluoride (LiF), tris-(8-hydroxyquinoline) aluminum $\left(\mathrm{Alq}_{3}\right), \mathrm{N}, \mathrm{N}$-diphenyl-N,N-bis(3-methylphenyl)-I, I'-diphenyl-4,4'-diamine (TPD), and In-doped zinc oxide (IZO), which were used as the top cathode, cathode buffer layer (CBL), emitting layer (EML), hole transport layer (HTL) and bottom anode, respectively. The emitting area was $2 \times 2 \mathrm{~mm}^{2}$. The LiF and Al cathode was deposited using thermal evaporation at the pressure of $6.8 \times 10^{-6} \mathrm{Torr}$, and TPD and $\mathrm{Alq}_{3}$ were deposited by thermal evaporation at $7.3 \times 10^{-6}$ Torr, respectively.

For current density versus voltage characteristics, a Keithley 2400 electrometer was used as a voltage source and current measurement equipment. The brightness of the OLEDs was investigated by using a Keithley 485 picoammeter to mea-

Table 1. Resistivitics, Hall mobilities, and carricr concentrations and work functions of pure IZO, IZO:H (UHV), and IZO:H $\left(\mathrm{H}_{2}\right)$ fílms determined from Hall effect measurements and digital Kelvin probe, respectively, at $300 \mathrm{~K}$

\begin{tabular}{|c|c|c|c|}
\hline & Pure IZO & $\mathrm{IZO}: \mathrm{H}(\mathrm{UHV})$ & $\mathrm{IZO}: \mathrm{H}\left(\mathrm{H}_{2}\right)$ \\
\hline Carrier concentration $\left(\mathrm{cm}^{-3}\right)$ & $4.4 \times 10^{19}$ & $3.5 \times 10^{20}$ & $3.6 \times 10^{20}$ \\
\hline Hall mobility $\left(\mathrm{cm}^{2} / \mathrm{Vs}\right)$ & 2.9 & 6.2 & 6.5 \\
\hline Resistivity $(\Omega \mathrm{cm})$ & $4.9 \times 10^{-2}$ & $2.9 \times 10^{-3}$ & $2.7 \times 10^{-3}$ \\
\hline Work function (eV) & 4.60 & 4.76 & 4.98 \\
\hline
\end{tabular}

sure the photocurrent induced by light emission from the OLEDs. All the experiments were performed under ambient atmosphere at room temperature.

\section{Results and Discussion}

In Figure 1, the crystalline structure and orientation of the deposited films were investigated by XRD. $\omega-2 \theta$ scans of pure IZO and IZO:H thin films are plotted. Figure 1(a) shows XRD spectrum of pure IZO film synthesized without hydrogen. Figures I(b) and (c) show XRD spectra of IZO films deposited with hydrogen. After deposition, sample (b) is maintained under a condition of UHV, and sample (c) is maintained under a condition of the $\mathrm{H}_{2}$ atmosphere $(50$ mTorr) in the chamber for $30 \mathrm{~min}$, respectively. The films were well oriented to the $c$-axis without showing any $\mathrm{In}_{2} \mathrm{O}_{3}$ and/or $\mathrm{ZnH}_{2-}$ related peaks in their XRD spectra and hardly exhibit any shift of the $(0002)$ peak $\left(2 \theta \approx 34.42^{\circ}\right)$. Based on the calculations by Van de Walle ${ }^{18}$ and Wardle et al, ${ }^{19}$ we expected that the any shifts of the peak for the IZO:H (UHV) and $\mathrm{IZO}: \mathrm{H}\left(\mathrm{H}_{2}\right)$ films can be interpreted in terms of the maintaining of $c$-axis lattice constant due to the interstitial hydrogen between the oxygen and zinc positions, pointing along the direction of the $c$-axis. The full-width at halfmaximum (FWHM) from the $(0002)$ peaks for the pure IZO, IZO:H (UHV), and IZO:H $\left(\mathrm{H}_{2}\right)$ films are determined to be $1.27^{\circ}, 1.26^{\circ}$, and $1.25^{\circ}$, respectively. The grain sizes estimated from the results of FWHM using the Scherrer's fornula are about $6.84,6.90$, and $6.95 \mathrm{~nm}$, respectively. Since the value of FWHM is inversely proportional to the grain size, the increase of the grain size as well as the improvement of the crystallinity lead to the decreasing the resistivity and the improving the Hall mobility due to diminishing in grain boundary scattering (see Table I).

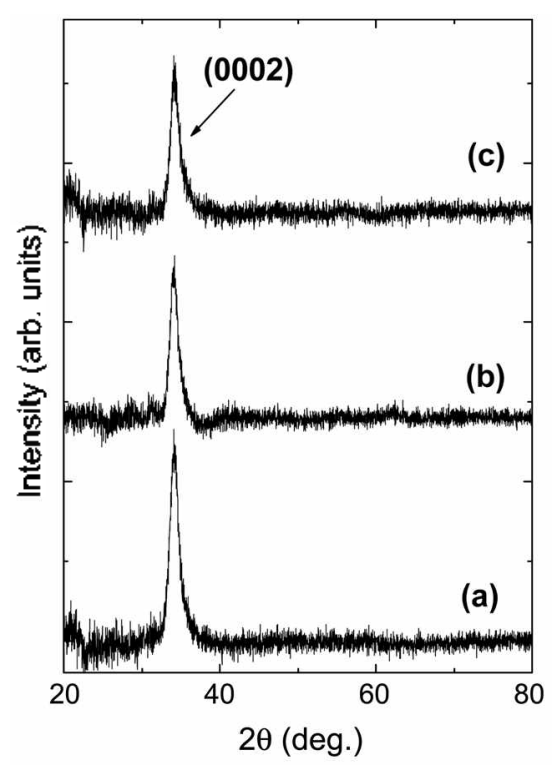

Figure 1. XRD spectra of IZO films grown on corning 7059 glass substrates under different conditions: (a) pure $\mathrm{IZO}$, (b) $\mathrm{IZO}: \mathrm{H}$ (UHV), and (c) IZO: $\mathrm{H}\left(\mathrm{H}_{2}\right)$. 
The resistivities, Hall mobjlities, and carrier concentrations for pure IZO, IZO:H (UHV) and IZO:H $\left(\mathrm{H}_{2}\right)$ films as determined from the Hall effect measurements using the van der Pauw technique, are summarized in the Table $\mathrm{I}$. The present pure IZO, IZO:H (UHV) and IZO:H ( $\left.\mathrm{H}_{2}\right)$ films were found to have $n$-type electrical conductivity. It can be seen that both Hall mobility and carrier concentration of the IZO films varied with the atmosphere used in the film preparation. In general, $\mathrm{ZnO}$ exhibits an $n$-type conductivity rising from the electrons in the conduction band. It has been widely considered that this $n$-type conductivity originated from the native defects such as $\mathrm{Zn}_{i}$ and $V_{0}$. Increasing the number of the native defects in the film gives rise to an increase in the carrier concentration and a decrease in the resistivity. Recently, it has been predicted that the incorporated hydrogen during the deposition of $\mathrm{ZnO}$ plays a role of a shallow donor by increasing the free carrier concentration. ${ }^{18,20}$ The resultant $\mathrm{ZZO}: \mathrm{H}$ (UHV) and $\mathrm{IZO}: \mathrm{H}\left(\mathrm{H}_{2}\right)$ films were definitely consistent with hydrogen being introduced as an interstitial and acting as a shallow donor. Hao et al. shows that the presence of hydrogen can enhance the Al doping efficiency that confirmed by measurement of the secondary ion mass spectroscopy and enhances thus the conductivity of $\mathrm{ZnO}: \mathrm{Al}$ films due to carrier concentration increasing. ${ }^{2}$ Thus, the increase in carrier concentration can be attributed to the native defect, substitution of the $\mathrm{Zn}^{2+}$ sites by $\mathrm{In}^{3+}$ ions, and interstitial hydrogen in the IZO films. The increasing tendency of mobility as well as resistivity and work function is also consistent with that of carrier concentration, expecting a hydrogen effect on OLEDs devices performance. Particularly, the electrical property of the IZO film maintained in UHV is similar than that of the IZO film maintained in $\mathrm{H}_{2}$. For fabrication of $\mathrm{IZO}: \mathrm{H}$ anodic film, the $\mathrm{IZO}: \mathrm{H}$ anode layer was deposited on glass substrate by pulsed DC magnetron sputtering with the $\mathrm{H}_{2}$ reactive gas, which may affects into the carrier concentration of the IZO:H film. This means that the growing $\mathrm{IZO}: \mathrm{H}$ film was exposed to an $\mathrm{H}$ plasma (so called $\mathrm{H}$ plasma injection), signifying that the $\mathrm{H}$ plasma injection can increases the reduction rate of IZO. We could interpret that hydrogen diffuses into the anodic film via grain boundaries at the surface and replaces the oxygen vacancies and thus considerably disturbs the increasing of oxidation state. To investigate hydrogen effects on the surface roughness of the IZO films that grew under various atmospheric conditions, AFM analysis was carried out. Surface morphology of the IZO films was sensitive to the hydrogen flow gas ratio. Surface roughnesses $\left(R_{m s}\right)$ for the pure IZO, IZO:H (UHV), and IZO:H $\left(\mathrm{H}_{2}\right)$ films were $10.8,6.5$ and $5.4 \mathrm{~nm}$, respectively, while the commercial ITO anode exhibited a surface roughness of $3.65 \mathrm{~nm}$. Noticeable thing is that $R_{r m s}$ of IZO:H $\left(\mathrm{H}_{2}\right)$ film is better than that of pure $\mathrm{IZO}$ film. Thus, during the deposition, hydrogen incorporated into the IZO films resulted in an improvement of the surface smoothness. Figure 2 illustrates the optical transmission spectra and the resultant band gap energy shift (insert) of the IZO films that grew under different atmospheric conditions. In the transmission spectra, the absorption edge was about $350 \mathrm{~nm}$ and

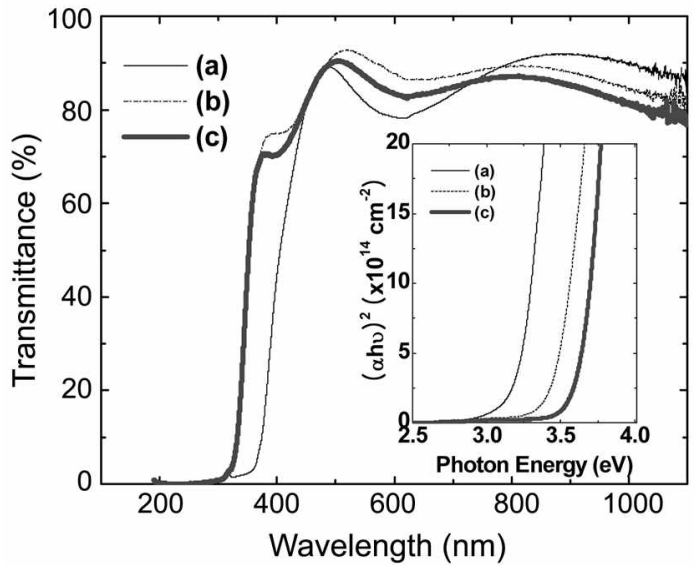

Figure 2. Optical transunittance spectra of IZO films prepared with different conditions: (a) pure IZO, (b) IZO:H (UHV), and (c) $\mathrm{IZO}: \mathrm{H}\left(\mathrm{H}_{2}\right)$. The insert shows the evolution of $E_{0}$ energy shift of the as-grown IZO:H films.

optical transmittance was about $85-90 \%$ in the UV-visible range. These results indicate that all IZO films could transmit UV and visible lights, and the IZO film would be a better anodic material for OLEDs. The optical absorption coefficient $\alpha$ is defined as $I=I_{0} e^{-\alpha \alpha}$, where $I$ is the intensity of transmitted light, $I_{0}$ is the intensity of incident light, and $d$ is the thickness of the IZO:H film. In the direct transition semiconductor, $\alpha$ and the optical band gap energy $\left(E_{0}\right)$ are related by $\alpha=\left(h v-E_{0}\right)^{1 / 2}$, where $h$ is the Plank's constant, and $v$ is the frequency of the incident photon. ${ }^{22}$ In order to determine the $E_{0}$ energy, square of the absorption coefficient $(\alpha h \cdot v)^{2}$ was plotted (see insert). Extrapolation of the linear portion of $\alpha$ to zero gives the value of the $E_{0}$ energy. In our study, $E_{0}$ energies of IZO films were detennined to be 3.23 , 3.37 , and $3.56 \mathrm{eV}$, respectively, for the pure IZO, IZO:H (UHV), and IZO:H $\left(\mathrm{H}_{2}\right)$ samples. $E_{0}$ energy of $\mathrm{ZZO}: \mathrm{H}$ thin films is larger than that of pure $\mathrm{ZnO}$ and it is observed that the value of $E_{0}$ energy shift increases with increasing carrier concentration, which is consistent with Burstein-Moss (BM) effect ${ }^{23}$ leading to a blue-shift of optical band-to-band transition.

To investigate the characteristics of OLEDs between commercial ITO and IZO (and IZO:H) anodes, the IZO:H films were prepared by pulsed DC magnetron sputtering methods under three different conditions. Three IZO and ITO films were used as an anode contacts for OLEDs, and the device configuration of OLEDs as shown in the insert of Figure 3 is the configuration of IZO or ITO $(200 \mathrm{~nm}) / \mathrm{TPD}$ $(32 \mathrm{~nm}) / \mathrm{Alq}_{3}(48 \mathrm{~nm}) / \mathrm{LiF}(1 \mathrm{~nm}) / \mathrm{Al}(68 \mathrm{~nm})$. Efficient electron injection from a cathode into the $\mathrm{Alq}_{3}$ layer can be obtained when the work function of a cathode is similar to the electron affinity of the $\mathrm{Alq}_{3}$ layer and efficient injection closely depends on the work function of $\mathrm{LiF} / \mathrm{Al}$ in the OLEDs structure. Figures 3 and 4 show the changes of current density versus applied voltage $(J-V)$ and brightness versus applied voltage $(B-V)$, respectively. $J-V$ and $B-V$ characteristics of all OLEDs except for pure IZO anodic electrode show typical diode behavior with current and 


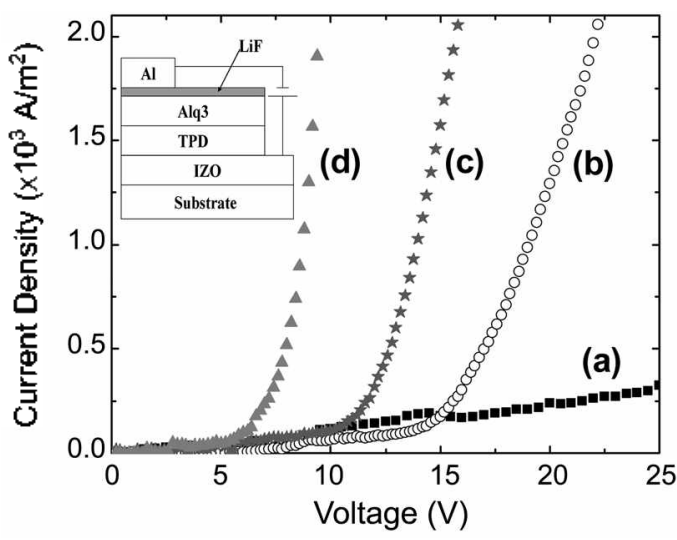

Figure 3. Curtent density $(J)$ versus voltage $(V)$ characteristics of the OLEDs: (a) pure IZO, (b) IZO:H (UHV), and (c) $\mathrm{IZO}: \mathrm{H}\left(\mathrm{H}_{2}\right)$, and (d) commercial ITO anodes.

power output observed in the forward bias. As shown in Figures $3,4,5$, and 6 , although the work functions of ITO and IZO anodes show the same value of $4.6 \mathrm{eV}$, the device performance of IZO anode is not happened. It is considered that in the EML, the charge imbalance between electron and hole increases due to the worse electrical properties such as carrier concentration, Hall mobility, resistivity, and work function and the higher $R_{r m s}$ of IZO anode rather than the pure ITO and hydrogenated IZO anodes. For the quantitative comparison in detail, the charge injection voltage and the turn-on-voltage were determined at the current density of $J=$ $1 \mathrm{~A} / \mathrm{m}^{2}$ and at the luminance of $B=1 \mathrm{~cd} / \mathrm{m}^{2}$ of Figures 3 and 4 , respectively. The tum-on-voltages (and the charge injection voltages) of $\mathrm{IZO}: \mathrm{H}(\mathrm{UHV})$ and $\mathrm{IZO}: \mathrm{H}\left(\mathrm{H}_{2}\right)$ based devices show $9.2 \mathrm{~V}(4.8 \mathrm{~V})$ and $6.2 \mathrm{~V}(2.2 \mathrm{~V})$, respectively, while the TTO device exhibits a turn-on-voltage of $3.4 \mathrm{~V}(1.4$ V). This result indicates that the tum-on-voltage shows a different trend with the charge injection voltage, and this discrepancy between the charge injection voltage and the turn-on voltage is probably attributed to the charge imbalance between the charge injection and the charge recombination in the EML. These device characteristics are mainly ascribed to the role of hydrogen doped IZO film in reducing the hole injection barrier between anode and HTL. From Figure 3, the drive voltages were also obtained at a current density of $1 \times 10^{3} \mathrm{~A} / \mathrm{m}^{2}$. The obtained drive voltages for $\mathrm{ZO}: \mathrm{H}$ (UHV) and $\mathrm{IZO}: \mathrm{H}\left(\mathrm{H}_{2}\right)$ anodes are 15 and $11 \mathrm{~V}$, respectively, while the ITO anode exhibits a drive voltage of $7.0 \mathrm{~V}$. The slight reduction in drive voltage for the $\mathrm{IZO}: \mathrm{H}\left(\mathrm{H}_{2}\right)$ anodic device may be due to an increase in the hole injection efficiency from the IZO:H layer into the TPD layer, as compared with device based on IZO:H (UHV) anode. In Figure 4, maximum light output of $\sim 8000 \mathrm{~cd} / \mathrm{m}^{2}$ is achieved at $16 \mathrm{~V}$ for the device based on the IZO:H $\left(\mathrm{H}_{2}\right)$ anode.

Figure 5 shows the extemal quantum efficiencies of the OLEDs. IZO:H (UHV), IZO:H $\left(\mathrm{H}_{2}\right)$, and commercial ITO anodes obtained maximum external quantum efficiencies to be $0.44 \%, 0.6 \%$, and $0.6 \%$ at $18 \mathrm{~V}, 13 \mathrm{~V}$, and $9 \mathrm{~V}$, respectively. The $120: \mathrm{H}\left(\mathrm{H}_{2}\right)$ anode is seen to have an extemal quantum efficiency similar to the commercial ITO anode.

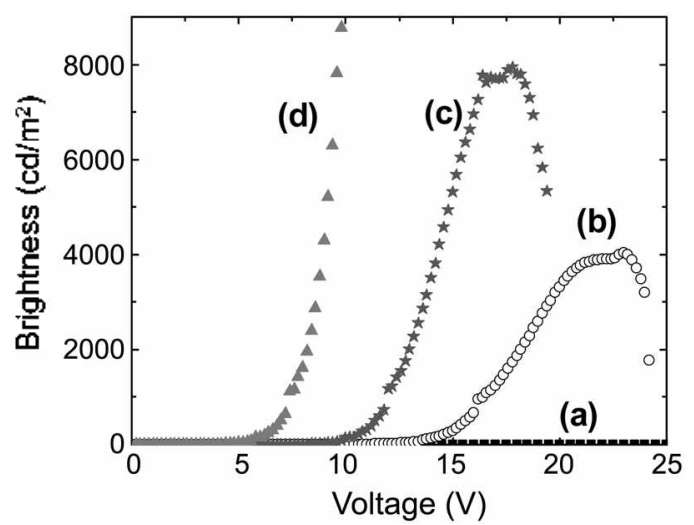

Figure 4. Brightness $(B)$ versus voltage $(V)$ characteristics of the OLEDs fabricated using the same films as Figure 3.

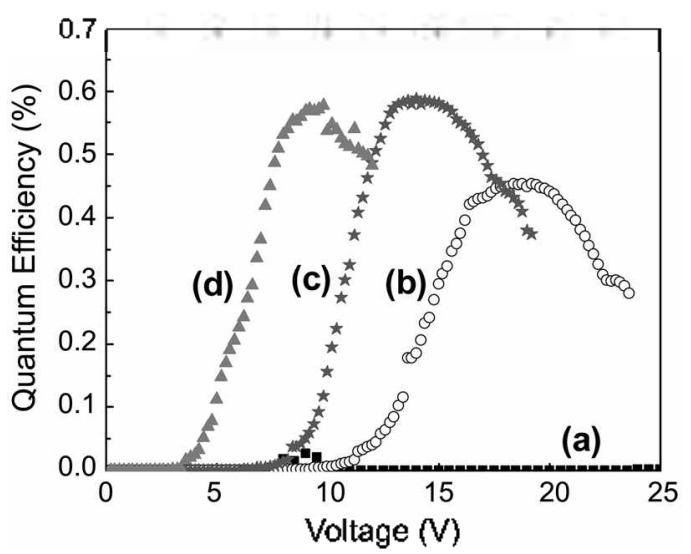

Figure 5. External quantum efficiency $(Q E)$ versus voltage $(V)$ characteristics of the OLEDs fabricated using the same films as Figure 3.

This indicates that the hydrogenated $\mathrm{ZZO}: \mathrm{H}\left(\mathrm{H}_{2}\right)$ film can substitute the commercial ITO electrode in the OLEDs.

The luminance efficiency versus current density is shown in Figure 6. The devices made of $\mathrm{IZO}: \mathrm{H}$ (UHV), IZO:H $\left(\mathrm{H}_{2}\right)$, and ITO anodes have the luminance efficiency of 2.6 $\mathrm{cd} / \mathrm{A}, 3.4 \mathrm{~cd} / \mathrm{A}$, and $3.4 \mathrm{~cd} / \mathrm{A}$, respectively. It found that the Juminance efficiency of the $\mathrm{IZO}: \mathrm{H}\left(\mathrm{H}_{2}\right)$ anode is almost $30 \%$ higher than that of the IZO:H (UHV) anode. The enhanced efficiency of $\mathrm{IZO}: \mathrm{H}\left(\mathrm{H}_{2}\right)$ device was attributed to the improved carrier balance and recombination. Jiang et al. reported that the differences in their surface work functions of anode films might be responsible for the differences in their current efficiency. ${ }^{11}$ As shown in the Table 1 , the work function of the hydrogenated IZO anodes measured to be 4.76 , and 4.98 eV for the IZO:H (UHV) and IZO:H $\left(\mathrm{H}_{2}\right)$ films, respectively. However, the obtained work function value $(4.6 \mathrm{eV})$ of the commercial ITO is lower than that of the hydrogenated IZO anodes. It is well known that the anodic film with a higher surface work function leads to a smaller energy barrier between the work function energy of the anode surface and the highest occupied molecular orbital (HOMO) of the HTL, which enhances the hole injection. Thus, the more electron-hole recombination within EML can be formed and the higher current efficiency was improved. ${ }^{12}$ 


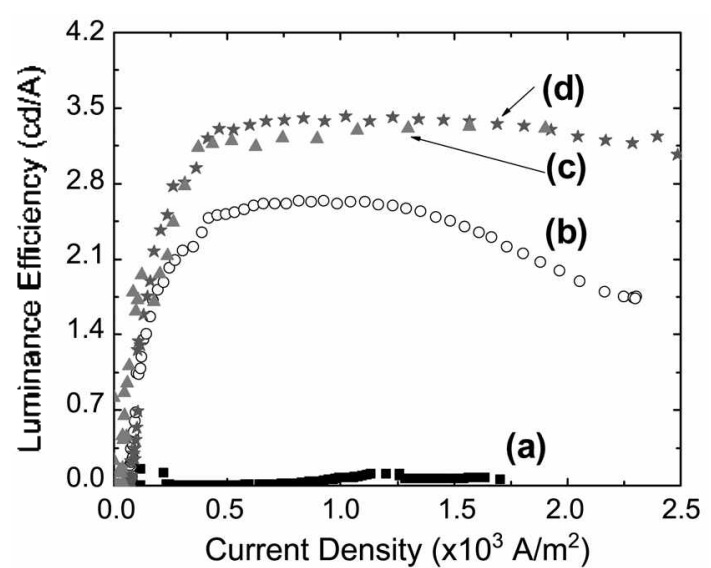

Figure 6. Luminance efficiency versus current density characteristics of the OLEDs fabricated using the same filuns as Figure 3.

Contrary to expectations, Figures 3 and 6 show that in spite of higher work function in the IZO:H anodes, these films exhibit slightly lower luminance efficiency and higher tunon-voltage than that of a commercial ITO anode, which is caused by higher surface roughness of IZO:H anodes than that of commercial ITO anode. We thus suggest that high surface work function and smooth surface roughness of IZO:H $\left(\mathrm{H}_{2}\right)$ film compared with IZO:H (UHV) film are attributable to improving the carrier injection properties at the IZO/TPD interface formed by surface modification technique such as $\mathrm{H}$ plasma injection. The relationship between the device performance and the work function of anodic transparent conducting oxide materials could be explained by the energy barrier height. This leads to more balanced injection of holes and electrons, and improvement of their recombination. Hence, the IZO:H film would be a better anode material for OLEDs. The present results suggest that optimized IZO:H films should be very useful and effective for both OLEDs and various other types of optoelectronic device such as FPDs, solar cells or passive photo devices. We believe that it is closely related to the possibility that hydrogenated IZO films may have different physical characteristics due to the hydrogen existence between bulk and surface, which is left for further studies.

\section{Conclusions}

Transparent conducting In-doped $\mathrm{ZnO}$ films were deposited on coning glass substrates by pulsed DC magnetron sputtering using a hydrogen-argon gas mixture at room temperature and controlled over the chamber atmosphere after deposition. The IZO:H films in the hydrogen controlled atmosphere showed a lower electrical resistivity of $2.7 \times$ $10^{-3} \Omega$ and a high transmittance of higher than $85 \%$ in the UV-visible region. The $\mathrm{IZO}: \mathrm{H}$ films were used as anode for OLEDs, and their device perfornances are also studied. The result showed that the device performance (charge injection voltage, turn-on-voltage, and current efficiency) was improved by hydrogen doping in the IZO anode. The OLED characteristics of the $\mathrm{IZO}: \mathrm{H}$ anode show excellent efficiency (11 V drive voltage) under a current density of $1 \times 10^{3} \mathrm{~A} / \mathrm{m}^{2}$, good brightness $\left(8000 \mathrm{~cd} / \mathrm{m}^{2}\right)$, and luminance efficiency $(3.4$ $\mathrm{cd} / \mathrm{A}$ ) of the light emitted from the devices, which is comparable to that of the commercial ITO anode. The results suggest that hydrogen controlled IZO:H films can possibly be applied to serve as an altemate anode material to ITO for the next generation of OLED and other optoelectronic devices.

Acknowledgments. This work was supported by the Korea Research Foundation Grant funded by the Korean Government (MOEHRD) (KRF-2005-005-J11902) and by the Ministry of Commerce, Industry, and Energy (MOCIE) through Advanced Material Process of Information Technology (AMPIT) (R12-2002-057-01001-0).

\section{References}

I. Forrest, S. R.; Bradley, D. D. C.; Thompson, M. E. Ad: Mater. $2003,15,1043$.

2. Kawano, K.; Ito, N.; Nishimori, T.; Sakai, J. Appl. Phys. Lett. 2006, 88, 073514 .

3. Kim, H.; Horwitz, J. S.; Kim, W. H.; Makinen, A. J.; Kafafi, Z. H.; Chrisey, D. B. Thin Solid Films 2002, 420-42I, 539.

4. Kim, H.; Gilmore, C. M.; Horwitz, J. S.; Pique, A.; Murala, H.; Kushto, G. P.; Schlaf, R.; Kafafi, Z. H.; Chrisey, D. B. Appl. Phys, Letl. 2000, 76, 259 .

5. Park, S.-M.; Ikegami, T.; Ebilhara, K. Jpn. J. Appl. Ph\%s. 2005. $44,8027$.

6. Suzuki, S.; Miyala, T.; Ishii, M.; Minami, T. Thin Solid Filns $2003,434,14$.

7. Kang, S. J.; Shin, H. H.; Yoon, Y. S. J. Korean Phys, Sac, 2007 , 5], 183.

8. Lin. Y. J.; Tsal, C. L.; Lu, Y. M.; Liu, C. J. J. Appl. Ph\%s. 2006, 99, 093501.

9. Kishimolo, S.; Yamada, T.; Ikeda, K.; Makino, H.; Yamamolo, T. Surface and Coatings Technolog: 2006, 201, 4000.

10. Park, Y. R.; Choi, S. L.; Lee, J. H.; Kim, K. J. J. Korean Phys, Sac. 2007, 50, 638 .

I1. Jeong, S. H.; Park, B. N.; Yoo, D. G; Boo, J. H.; Jung, D. J. Korean Phys. Soc. 2007, 50,622.

12. Jiang, X.; Wong, F. L.; Fung M. K.; Lee, S. T. Appl. Phss. Lett. $2003,83,1875$.

13. Shin, Y. J.; Kim, K. S.; Park, N. G.; Ryu, K. S.; Chang, S. H. Bull. Korean Chem. Soc. 2005, 26, 1929.

14. Kim, K. S.; Kang. Y. S.; Lee, J. H.; Shin, Y. J.; Park, N. G.; Ryu, K. S.; Chang, S. H. Bull. Korean Chem. Soc. 2006, 27, 295.

15. Kim, K. J,; Park, Y, R. Appl. Phys, Lett. 2001, 78, 475.

16. Qadri, S. B.; Kim, H.; Horwitz, J. S.; Chrisey, D. B. J. Appl. Phys. $2005,48,6564$.

17. Kim, J. H.; Ahn, B. D.; Lee, C. H.; Jeon, K. A.; Kang, H. S.; Lee, S. Y.J. Appl. Phts. 2005, 100, 113515.

18. Van de Walle, C. G. Phys. Rev. Lett. 2000, 85, 1012.

19. Wardle, M. G.; Goss, J. P.; Briddon, P. R. Appl. Phys, Lett. 2006, 88,261906 .

20. Ishii, D.; Kinbara, K.; Ishida, Y.; Ishii, N.; Okochi, M.; Yohda, M.; Aida, T. Nattre $2003,423,626$.

21. Hao, X. T.; Zhu, F. R.; Ong, K. S.; Tan, L. W. Senicond. Sci. Technol. 2006, 2l, 48 .

22. Ziegler, E.; Heinrich, A.; Oppermann, H.; Stover, G Phys, Status Solidi (a) $1981,66,635$.

23. Burstein, E. Phss. Rev 1954, 93, 632; Moss, T. S. Proc. Phys. Soc. London, Ser, B 1954, 67, 775 . 